with many well chosen illustrations of instruments - that the astronomer at least was not averse to making observations of the real world. But to what extent he and other mediaeval scholars were doing real science is a question best answered by reading the collection as a whole.

J. D. North is at the Filosofisch Instituut der Rijksuniversiteit, Groningen, The Netherlands.

\section{Formal theory of ecosystems}

Theoretical Systems Ecology. Edited by E. Halfon. Pp. 516. (Academic: New York and London, 1979.) £43; £27.95.

THE opening sentence of the preface to this book claims that systems ecology is having a large impact upon all aspects of environmental research, and that the systems approach, with its body of concepts and techniques, has broadened the ecologists' perspectives and attracted students into ecology from other disciplines. The preface goes on to suggest, however, that there has been a lack of communication between theoreticians and modellers and field ecologists, and that the purpose of this book is to try to bridge the gap in communication.

Is it true that systems ecology, or the application of systems theory to ecology, is having an impact on environmental research? Many ecologists would disagree with the statement, and there are as yet relatively few examples of practical action on environmental problems having been taken as a result of studies of systems ecology. There is certainly much understanding of the ways in which organisms respond to changes in their environment, and some of this modelling is based on concepts derived from studies of control systems. I suspect, however, that one of the reasons for the lack of communication between theoreticians and field ecologists is that the dependence of ecological models on systems theory is less than is believed by the theoreticians. Much of the modelling still based on statistical concepts developed even earlier than those of the systems analysts.

This volume contains 20 chapters written by 28 contributors, and divided into four main sections. Part I discusses some fundamental system problems, particularly the aggregation problem and its relation to sampling. Part II includes information on modelling approaches and philosophy, with emphasis on model structure and model properties. Part III introduces methodologies and computer techniques of system identification. Part IV contains studies on model analysis, principally of structural properties such as stability, flow analysis and general systems properties.

Undoubtedly, the book contains original contributions in theoretical systems ecology which may be important as a basis for future developments. As most of the chapters are almost unintelligible to anyone not already well versed in systems theory, however, the book does little, if anything to bridge the gap between theoreticians and practical ecologists. Indeed, until theoreticians can learn to state their conclusions in simple and unambiguous plain language, it is doubtful if systems ecology will really have the impact that systems analysts claim for it. At present, those of us who are attracted by this approach to ecology too of ten mistake our models for the real world, and are content to leave our description of these systems in the mathematical terms for which they were derived. Those who have to use our research find it difficult to translate from the mathematics to the plain statements of every-day usage.

One of the problems that need to be solved is terminology. The terms used in this book are claimed to be as uniform as possible, but different names are frequently used for the same concept or the same name for different concepts. The problem is said to be typical not only of systems ecology but also of general systems theory. This confusion seems to derive from the fact that the contributors follow the terminology of quite different theories of general systems, and the concepts of these theories do not often overlap. An early priority for theoreticians, therefore, would seem to be the resolution of these inconsistencies, and the development of a formal theory of ecosystems as a working definition for ecological research.

J.N.R. Jeffers

J.N.R. Jeffers is Director of the Institute of Terrestrial Ecology, Natural Environment Research Council, Grange-over-Sands, Cumbria, UK.

\section{Primary energy supply prospects}

World Energy: Looking Ahead to 2020. Report by the Conservation Commission of the World Energy Conference. (IPC Science and Technology Press: Guildford, UK, 1978.) £12.50; \$32.50.

THE objectives of the Conservation Commission were to evaluate, for the period 1985-2020, future primary energy supply prospects and to identify possible courses of action to overcome potential shortfalls in energy availability, particularly the impending decline of oil and gas supplies. The report is based on the work of a series of specialist study groups, dominated by OECD-centred experts.

The Commission notes that for industrialised nations there seems to be a decreasing requirement for additional energy supplies with increasing economic growth; by 2020 , it seems that the energy coefficient might decline to one half its current average level in these countries (but it is unclear whether measurements are made in primary, delivered or final useful energy terms). In the case of developing countries, however, the incremental ratio of energy demand to economic growth will continue to increase.

Somewhat surprisingly, given the upsurge in public opposition to virtually any major energy siting decision (for example, refineries, coal mines and nuclear stations) and evidence of rising real capital costs, the Commission argues that "the energy supply which could be attained in the next few decades is easier to predict than is the demand for energy, because it is determined primarily by technology". The Commission forecasts that the share of conventional crude oil in total world primary energy supplies will decline from $40 \%$ at present to about $10 \%$ by 2020 , with natural gas then contributing $20 \%$, nonconventional petroleum (for example, tar sands, shales, geopressure zone gas) about $5 \%$, coal $25 \%$, and renewable sources $10 \%$, with the balance, $30 \%$, being provided by nuclear energy from fission.

Total primary energy demand is estimated to reach three times today's level of $9 \times 10^{9}$ metric tons of coal equivalent by 2020 , involving major efforts in all energy resource areas. In particular, it implies tripling coal production, "doubling nuclear power plant capacity every six years" and substantial growth in solar energy.

The report envisages that about $30 \%$ of the energy that would otherwise have been needed by 2020 could be saved through technological improvements in conversion and utilisation. Further conservation, about $17 \%$, is considered feasible through structural changes in the more mature econumies, including saturation in car transportation and domestic energy demand and reduced utilisation by the energy-intensive industries.

The study is a valuable contribution to the literature, even though it omits sufficient discussion of issues such as public opposition, potential climatic impacts of increased energy consumption, geopolitical stresses likely to be prompted by international disparities in energy resource endowments, criteria for allocation of $\mathrm{R}$ and $\mathrm{D}$ expenditure, and more speculative and normative assessments of alternative world futures.

John Chesshire

John Chesshire is a Fellow of the Science Policy Research Unit, University of Sussex, Brighton, $U K$, and a member of the Unit's Energy Programme Group. 